DOI: 10.14451/1.194.39

\title{
ЭКОНОМИЧЕСКИЙ И ПОЛИТИЧЕСКИЙ СОЮЗ СТРАН БРИКС
}

\author{
(c) 2021 Байрамкулов Магомед Алиевич \\ магистрант \\ Финансовый университет при Правительстве Российской Федерации, Россия, Москва \\ E-mail: bayramkulov09@gmail.com \\ https://orcid.org/0000-0002-6340-7073
}

Предмет / тема: Статья посвящена анализу интеграционного объединения БРИКС, причинах и способах его организации, и целях, которые были поставлены перед ним. В статье рассматриваются результаты, к которым удалось прийти объединению в период его функционирования, приведены также различные точки зрения на результаты работы.

Цели / задачи: Определить проблемы функционирования БРИКС, как альтернативу современной однополярной финансовой организации.

Методология: В процессе исследования были применены следующие методы: теоретический анализ, анализ нормативно-правовой базы, трендовый анализ.

Результаты / выводы: В ходе проведения исследования были выделены основные направления взаимосвязи между интеграционным объединениям и международным движением финансов. Показаны ключевые преимущества и недостатки БРИКС. Проанализировано воздействие интеграционных объединений на мировую финансовую архитектуру и мировую экономику.

Ключевые слова: БРИКС, глобализация, мировая финансовая архитектура, развития интеграционных объединений, Всемирный банк, Международный валютный фонд, интеграционные процессы.

В условиях постоянно растущей глобализации необходима модернизация сложившейся однополярной модели мировой экономики с устоявшимся лидером в качестве Соединенных Штатов Америки. Таким образом, многие развивающиеся страны предлагают собственные подходы к реформированию системы мирового регулирования.

Одним из таких объединений развивающихся стран является БРИКС (Бразилия, Россия, Индия, Китай и Южная Африка) - сложившееся социально-экономическое и политическое партнерство между крупнейшими развивающимися экономиками, созданное в рамках Петербургского экономического форума (ПЭФ) 2006 года.

Страны БРИКС нацелены на установление новой экономической системы, в основе которой находился бы равный доступ стран к рынкам сбыта и источникам финансирования. В связи с этим, данный союз часто рассматривается не только как альтернативный полюс политического влияния, но и как начало принципиально новой организации будущего мироустройства.

Важно отметить, что БРИКС имеет возможность модернизироваться в некий локомотив, способный влиять на сложившуюся экономическую конъюнктуру и устанавливать более справедливые правила международных экономических отношений. Именно поэтому изучение опыта функционирования данного союза представляется актуальным в современных реалиях процесса сдвига мировой парадигмы.

Как было отмечено ранее, БРИКС функционирует уже 12 лет, в течение которых союз руководствуется следующими основными принципами*:

1. Укрепление многосторонних начал в глобальной политике, продвижение общих интересов стран БРИКС на мировой арене.

2. Развитие торгово-экономического и финансового сотрудничества.

3. Сотрудничество в гуманитарной и культурной сферах, укрепление контактов между людьми.

Большое внимание стоит уделить основным макроэкономическим показателям странучастниц БРИКС. Как можно заметить на Диаграмме 1, абсолютными лидерами по приросту среди стран объединения являются Индия и Китай - ВВП Индии и Китая составляют 2,9 и 14,3

\footnotetext{
* Приоритеты председательства Российской Федерации в БРИКС - BRICS Russia - https://brics-russia2020.ru/
} 
трлн. долл. США соответственно по состоянию за 3 квартала 2020 года*.

Очевидным является и тот факт, что прирост ВВП в данных странах выше, чем общий мировой ВПП, и, более того, в перспективе до 2025 позиции стран снижаться не будут.

Что касается, других стран БРИКС - ВВП Бразилии составляет 1,8 трлн. долл. США, ВВП России - 1,7 трлн. долл. США, ВВП Южной Африки $-0,35$ трлн. долл. США. Для сравнения на Диаграмме 2 представлена пятерка лидеров стран по ВВП - США, Китай, Япония, Германия и Индия, что не может не характеризовать организацию БРИКС как весьма перспективную.
Говоря о позициях России в данном аспекте - она занимает 11 место из 203 стран списка, Бразилия - 9 место и Южная Африка - 37 место.

За последние 5 лет ВВП стран БРИКС рос быстрее мирового ВВП (среднегодовые темпы роста составили 5,31\% и 3,45\% соответственно). В результате доля БРИКС в мировом ВВП по ППС увеличилась с 30,7\% в 2015 году до 33,4\% в 2019 годуж*.

С 2016 года БРИКС больше G7 по объему ВВП по ППС. Доход на душу населения и, соответственно, благосостояние населения стран БРИКС растут (в 2009-2019 годах ВВП по ППС на душу населения в постоянных ценах вырос на 5\% в

* The World Bank: Gross Domestic Product 2020. The World Bank 2020.

** Данные Международного валютного фонда (МВФ)

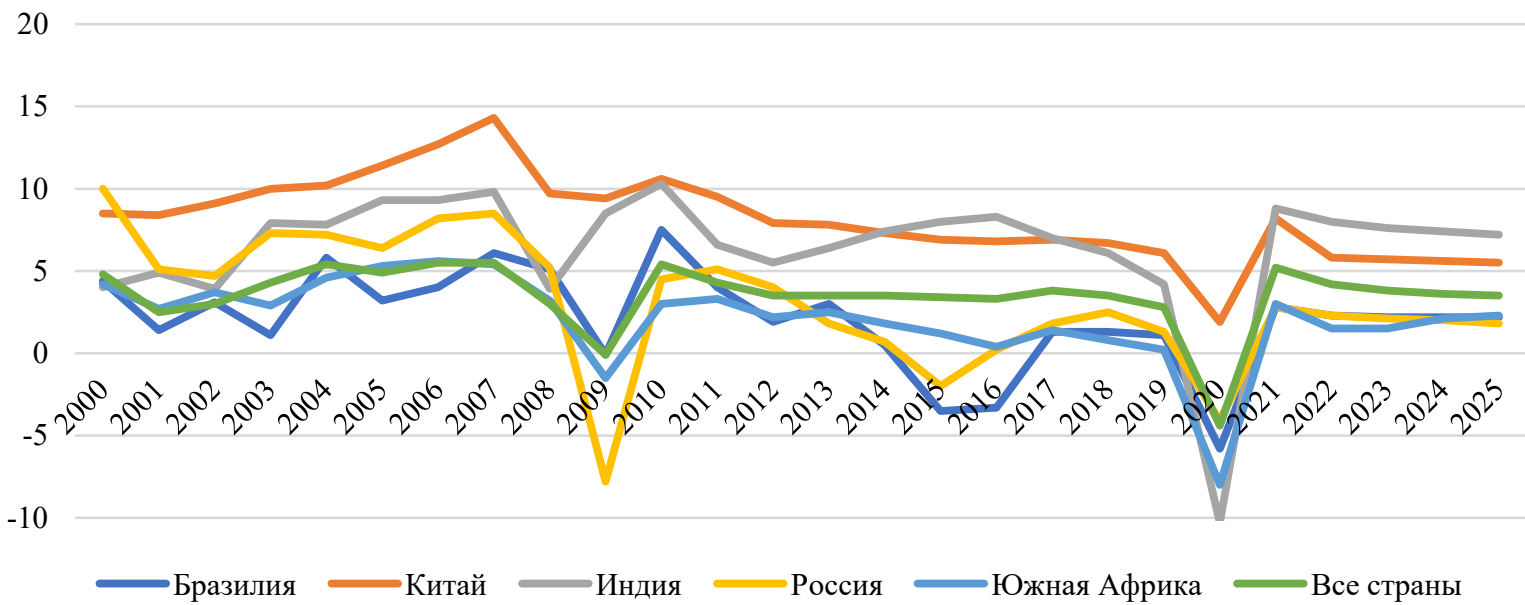

Диаграмма 1. Реальный ВВП (\% к предыдущему году) с 2000 по 2025 гг. Источник: Международный валютный фонд

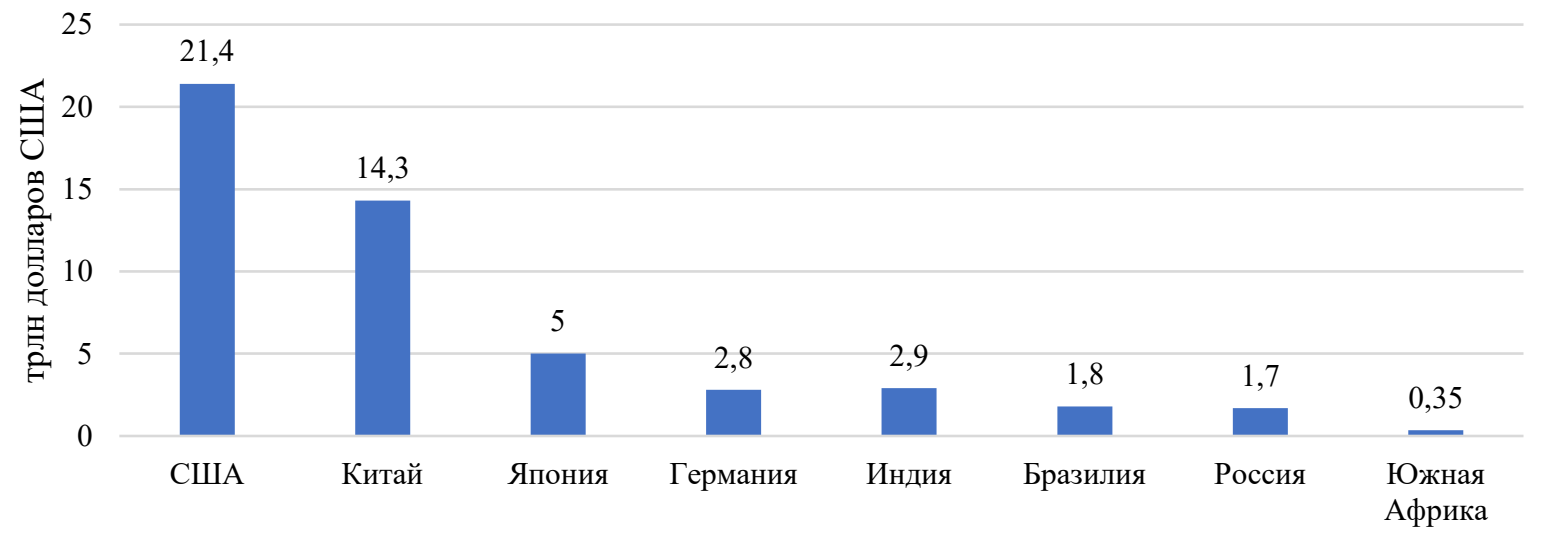

Диаграмма 2. ВВП стран за 3 квартала 2020 года Источник: The World Bank: Gross Domestic Product 2020 
Бразилии, почти на $100 \%$ в Китае, на $72 \%$ в Индии, на $18 \%$ в России, на $2 \%$ в ЮАР)

Позиции стран БРИКС в международных экономических отношениях укрепляются: по данным ВТО и ЮНКТАД, их общая доля в мировом товарном экспорте достигает 19\%, в импорте превышает $16 \%$, в сфере услуг экспорт остается на уровне $13 \%$, импорт $-15 \%$, в мировом накопленном ПИИ - 9,5\%, накопленном ПИИ за рубежом - 9\% (4,4\% в 2009 году $)^{* * *}$.

Позиции в рейтинге Global Innovation Index за последние пять лет улучшились практически для всех стран-членов БРИКС, что адекватно отражает успешность национальных инновационных и информационных систем, а также развитие инновационно-ориентированного сотрудничества в рамках группы (Таблица 1).

Из числа стран БРИКС в 2019 году Китай имел лучший результат Глобального инвестиционного индекса, заняв 14-ю позицию в рейтинге. В 2019 году Россия переместилась на 46-е место по сравнению с 48-м в 2015 году. Индия поднялась на 29 мест, Бразилия - на 3 места. ЮАР опустилась на 3 места по сравнению с 2015 годом: с 60-го на 63-е место в рейтинге.

Бразилия имеет самый низкий показатель Глобального инвестиционного индекса среди стран БРИКС - 66-я позиция в рейтинге, однако по сравнению с 2015 годом Бразилия поднялась на 4 места.

Отсутствие прямолинейного и непрерывного роста данного показателя не позволяет делать общие предположения о прогрессе БРИКС в этой области.

Однако благодаря инвестициям, институци- ональной, образовательной и культурной деятельности, рыночным реформам, глобализации и другим важным действиям все страны БРИКС демонстрируют сильные позиции по различным показателям Глобального инвестиционного индекса, то есть, несмотря на неравномерный рост, очевидного разрыва в прогрессе экономик БРИКС на пути к экономике знаний нет.

Согласно Global Competitiveness Report 2019, в котором представлен рейтинг стран на основе значительного количества показателей Бразилия занимает 28 место из 141 (в 2014 году - 28 место), Россия - 53 место (в 2014 году -43 ), Индия - 56 место (в 2014 году - 60 место), Китай 57 место (в 2014 году - 89 место) и Южная Африка -71 место (в 2014 году - 71 место).

Что касается поддержки предпринимательства и скорости развития бизнеса, то страны БРИКС не находятся на лидирующих позициях. На основе Ease of Doing Business Index, публикуемом Всемирным банком, самое высокое место занимает Россия на 43 месте (+41 место по сравнению с 2015 годом) и Бразилия - 62 место (-34 места по сравнению с 2015 годом).

Изменение данных позиций не является однозначно позитивным для некоторых стран БРИКС. Взаимное экономическое сотрудничество развивается, но довольно медленно, в то же время торговля и инвестиции между странами БРИКС составляют лишь небольшую часть их общих показателей.

Позиции стран БРИКС в международных экономических отношениях укрепляются: по данным ВТО и ЮНКТАД, их общая доля в мировом товарном экспорте достигает 19\%, в им-

* Данные Международного валютного фонда (МВФ).

** Данные UNCTAD

Таблица 1. Позиции стран БРИКС в рейтинге Глобального инновационного индекса

\begin{tabular}{|c|c|c|c|c|c|c|c|}
\hline $\begin{array}{c}\text { Место в рей- } \\
\text { тинге (Место } \\
\text { за } 2015 \text { год) }\end{array}$ & Страна & $\begin{array}{c}\text { Глобальный иннова- } \\
\text { ционный индекс }\end{array}$ & 奈 & 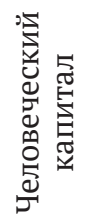 & 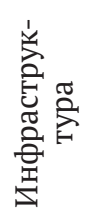 & 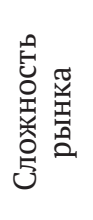 & 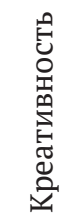 \\
\hline $66(70)$ & Бразилия & 33.8 & 58.9 & 36.0 & 46.8 & 44.2 & 23.0 \\
\hline $46(48)$ & Россия & 37.6 & 60.9 & 48.3 & 47.1 & 49.4 & 27.1 \\
\hline $52(81)$ & Индия & 36.6 & 59.5 & 33.5 & 43.0 & 56.3 & 33.5 \\
\hline $14(29)$ & Китай & 54.8 & 64.1 & 47.6 & 58.7 & 58.6 & 57.1 \\
\hline $63(60)$ & Южная Африка & 34.0 & 65.9 & 30.4 & 41.1 & 58.6 & 23.9 \\
\hline
\end{tabular}

Источник: GII Report 2019, https://www.globalinnovationindex.org/gii-2019-report 
порте превышает 16\%, в сфере услуг экспорт остается на уровне $13 \%$, импорт $-15 \%$, в доли мировых прямых иностранных инвестиций 19,5\% (15,4\% в 2009 году) (Диаграмма 3).

За последние 5 лет доля взаимного экспорта в общем объеме внешней торговли стран БРИКС увеличилась с 7,7\% в 2015 году до 10,0\% в 2019 году, внутрирегиональный импорт составил $11,9 \%$ и $12,9 \%$ соответственно. Региональные производственно-сбытовые цепочки расширились, а доля промежуточных продуктов во внутрирегиональной торговле БРИКС приблизилась к $60 \%$ *

Нельзя не сказать об укреплении финансовой и институциональной инфраструктуры содействия инвестициям БРИКС: Новый банк развития (НБР) значительно увеличил свой кредитный портфель, начал функционировать механизм технической помощи НБР. К примеру, Банк поддержал 14 энергетических проектов во всех пяти странах на общую сумму более 3,5 млрд. долл. США. Более того механизм межбанковского сотрудничества обеспечил более тесное сотрудничество национальных банков развития.

Что касается научных разработок, то в рамках Рамочной программы БРИКС по науке, технологиям и инновациям (BRICS STI Framework
Programme) было начато десять исследовательских проектов в энергетическом секторе.

За последние 10 лет товарооборот сельскохозяйственной продукции и продовольствия между странами БРИКС почти удвоился в стоимостном выражении: с 19,883 млн. долл. США в 2010 году до 39,892 млн. долл. США в 2019 году. Этот результат особенно показателен на фоне общемировой динамики - среднегодовой рост товарооборота в стоимостном выражении между странами БРИКС составил 9,6\% против общемировых 3,3\%**.

Лидером по росту товарооборота сельскохозяйственной продукции между странами БРИКС является Россия $-258 \%$, за ней следуют ЮАР - 146\%, Индия - 131\%, Бразилия - 94\%. Значительный рост наблюдается и в физическом выражении: с 34653 тыс. тонн в 2010 году до 74205 тыс. тонн в 2019 году, что составляет 2,14 раза. Это свидетельствует о росте коммерческой привлекательности национальных рынков сельскохозяйственной продукции и снижении тарифных и технических барьеров в торговле.

Одной из основных задач в области финансового сотрудничества БРИКС является необходимость повышения потенциала и эффективности механизма условных резервов как механизма

* Implementation of the Strategy for BRICS Economic Partnership in the period 2015-2020 - BRICS Russia Expert Council

*** Леонова О.Г., Попова Н. В.Новые приоритеты БРИКС. Навстречу 12-му саммиту БРИКС в России // Социальногуманитарные знания. 2020. № 2. URL: https://cyberleninka.ru/article/n/novye-prioritety-briks-navstrechu-12-musammitu-briks-v-rossii

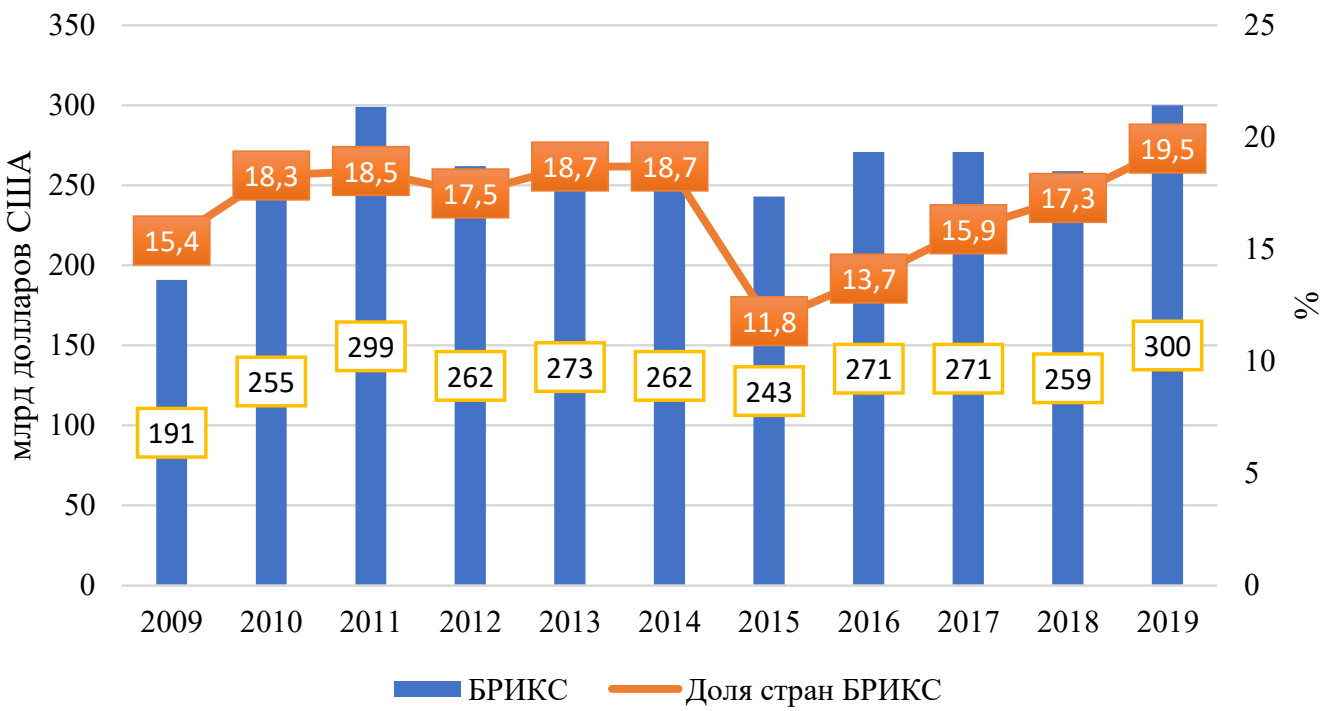

Диаграмма 3. ПИИ в страны БРИКС за 2009-2019 гг. Источник: UNCTAD 
поддержки платежного баланса государствчленов БРИКС с учетом проблем долларовой ликвидности США.

Еще одной важной задачей является создание единой расчетно-платежной системы стран БРИКС для обеспечения расчетов в национальных валютах, что должно, в частности, снизить транзакционные издержки трейдеров и инвесторов. Расширение использования национальных валют стран БРИКС позволит снизить зависимость от быстро меняющейся ситуации в мировых экономических центрах.

В предстоящий период потребуются также дополнительные усилия БРИКС для полной реализации реформы квот и управления МВФ, с тем чтобы вес БРИКС в мировой экономике был приведен в соответствие с весом механизма принятия решений МВФ.

В основном были созданы механизмы межведомственного сотрудничества, координации и совместных действий стран БРИКС, а также приняты некоторые практические меры (в частности, в области конкурентной политики и интеллектуальной собственности).

Однако до сих пор не приняты нормативные документы БРИКС (за исключением документов в сфере финансового сотрудничества). Институциональная связность рассматривается отдельно в соответствии со стратегией экономического партнерства БРИКС, но учитывая, что она может быть прослежена в рамках других секторальных частей стратегии, представляется, что нет необходимости в специальном подразделе для этой конкретной темы.

Институциональная взаимосвязанность является неотъемлемой частью общей отраслевой деятельности, которая включает создание совместных институтов, межведомственную координационную деятельность, разработку рабочих программ и планов и их практическую реализацию, создание общих платформ и информационных ресурсов, организацию специальных мероприятий, реализацию совместных проектов и т.д.

Физическая отдаленность создает ряд проблем, характерных для стран, расположенных в различных частях земного шара. Многие проведенные мероприятия, такие как министерские встречи по сотрудничеству в области транспорта и последующее подписание Меморандума о взаимопонимании по региональной авиации и практике обмена опытом организации город- ской мобильности, более 20 связанных с транспортом проектов, поддерживаемых в рамках НБР БРИКС на общую сумму более 5,5 млрд. долл. США, а также совместные исследования при содействии программы BRICS STI Framework Programme, помогают сделать вывод, что эта область сотрудничества остается на ранних стадиях развития и многое еще предстоит сделать для обеспечения связности, поддерживающей сотрудничество БРИКС.

БРИКС также стремится развивать сотрудничество в социально важных областях и содействовать развитию человеческого капитала и связям между людьми с момента своих первых встреч. Стратегия экономического партнерства БРИКС предусматривает широкий спектр мероприятий в области образования, туризма, бизнеса и мобильности рабочей силы, направленных на дальнейшее стимулирование взаимодействия между странами, народами и обществами БРИКС, укрепление взаимопонимания и дружбы.

Члены БРИКС считают жизненно важным совместную работу по обеспечению эффективного функционирования многосторонней торговой системы, воплощенной в ВТО. Они вновь заявили о своей поддержке ВТО и выразили готовность продолжать работу по обеспечению основанного на правилах, прозрачного, недискриминационного, открытого, свободного и инклюзивного характера международной торговли. Тем не менее, несмотря на согласованные принципы и общую готовность членов БРИКС совместно работать над преодолением кризиса ВТО, все еще существуют примеры несоблюдения правил и принципов ВТО. Таким образом, члены БРИКС могут участвовать в конструктивном и открытом обсуждении путей решения общих проблем и проблем отдельных стран с учетом правил и принципов ВТО.

Во многих передовых областях науки, техники и инноваций достижения стран БРИКС неоспоримы, а по ряду направлений, таких как компьютерные и цифровые технологии, космические и коммуникационные технологии, ракетостроение, ядерные, нано - и медицинские методологии, страны пятерки занимают лидирующие позиции в мире. Взаимодействие стран БРИКС по всем основным направлениям содействия Четвертой промышленной революции укрепляется, а необходимый человеческий потенциал неуклонно растет.

Таким образом, оценка результатов реали- 
зации стратегии экономического партнерства стран БРИКС свидетельствует о значительном вкладе мероприятий, направленных на реализацию целей и задач союза. Более того, создается концептуальная новая альтернатива имеющимся международным финансовым институтам (НБР), разрабатываются более справедливые правила международных валютно-финансовых отношений, что, в свою очередь, не может не говорить о развитие мировой многополярности.
Однако, несмотря на общий позитивный вектор экономического развития и взаимодействия в рамках БРИКС, сохраняются некоторые сдерживающие факторы, обусловленные неравномерностью экономической и инновационной динамики отдельных стран-участниц, неодинаковой скоростью и глубиной структурных реформ, инновационными преобразованиями в национальных экономиках, их адаптацией к новым вызовам развития

\section{Библиографический список}

1. Ваутерс Я., Ван Керкховен Позиции «Группы двадцати» и БРИКС по торговле и инвестициям: тенденции и политика // Вестник международных организаций: образование, наука, новая экономика. 2017. № 3.

2. Леонова Ольга Георгиевна, Попова Наталья Валерьевна Новые приоритеты БРИКС. Навстречу 12-му саммиту БРИКС в России // Социально-гуманитарные знания. 2020. № 2.

3. Цаплина Екатерина Игоревна Эволюция БРИКС: проблемы и перспективы // Актуальные проблемы современных международных отношений. 2017. № 9.

4. Хейфец Борис Аронович БРИКС: повестка для России на саммите - 2020 в Челябинске // Российский внешнеэкономический вестник. 2019. № 1.

5. Ярыгина И. З. Механизмы экономического развития БРИКС - ЕС // Большая Евразия: Развитие, безопасность, сотрудничество. 2018. № 1-1.

6. BRICS and economic development: a multidisciplinary perspective - IOR international press - [Электронный ресурс] - Доступ: http://www.nkibrics.ru/system/asset_publications/data/5fa0/19df/6272/6945/d545/0000/ original/BRICS_and_Economic_Development.pdf?1604327903 (Дата обращения 10.11.2020).

7. Implementation of the Strategy for BRICS Economic Partnership in the period 2015-2020 Overview BRICS Russia Expert Council - [Электронный ресурс] - Доступ: https://brics-russia2020.ru/images/113/92/1139279.pdf (Дата обращения 10.11.2020).

8. BRICS science, technology and innovation (STI) calendar of activities 2020-2021 - [Электронный ресурс] - Доступ: https://brics-russia2020.ru/images/113/92/1139206.pdf (Дата обращения 10.11.2020).

9. Economic growth for an innovative future BRICS business - Council annual report Brasilia - [Электронный ресурс] - Доступ: http://brics2019.itamaraty.gov.br/images/documentos/lowres_cni_cebrics_cupula_en_1.pdf (Дата обращения 10.11.2020).

10. Сайт Международного валютного фонда - [Электронный ресурс] - Доступ: https://www.imf.org/external/ russian/index.htm (Дата обращения 10.11.2020).

11. Сайт UNCTAD - [Электронный ресурс] - Доступ: https://unctad.org/

12. Global Competitiveness Report 2019 - [Электронный ресурс] - http://www3.weforum.org/docs/WEF_TheGloba 1CompetitivenessReport2019.pdf (Дата обращения 10.11.2020).

13. Doing business 2020 - [Электронный ресурс] - Доступ: https://www.doingbusiness.org/en/reports/globalreports/doing-business-2020 (Дата обращения 10.11.2020).

14. GII Report 2019 - [Электронный ресурс] - Доступ: https://www.globalinnovationindex.org/gii-2019-report (Дата обращения 10.11.2020).

15. The World Bank: Gross Domestic Product 2020 - [Электронный ресурс] - Доступ: https://www.worldbank.org/ en/publication/global-economic-prospects (Дата обращения 10.11.2020). 